\title{
ANÁLISE SAZONAL DA VEGETAÇÃO DO CERRADO POR MEIO DE DADOS DO SENSOR MODIS NO DISTRITO FEDERAL (BRASIL)
}

\author{
SEASONAL ANALYSIS OF CERRADO VEGETATION BY MEANS \\ OF MODIS DATA IN THE DISTRITO FEDERAL (BRAZIL)
}

\author{
ANALYSE SAISONNIERS DE LA VEGETATION DE CERRADO PAR \\ DONNÉES DU CAPTEUR MODIS DANS LE DISTRICT FÉDÉRAL (BRÉSIL) \\ Greison Moreira de Souza - Instituto Nacional de Pesquisas Espaciais \\ - São José dos Campos - São Paulo - Brasil \\ greison.souza@inpe.br
}

\begin{abstract}
Helen da Costa Gurgel - Universidade de Brasília - Brasília - Distrito Federal - Brasil
helengurgel@unb.br
\end{abstract}

Pierre Mazzega Ciamp - Institut de recherche pour Le développement - Toulouse - França

pierre.mazzega@ird.fr

\section{Resumo}

0 presente estudo visa caracterizar o comportamento sazonal da vegetação do Cerrado por meio de índices de vegetação (NDVI e EVI) do sensor MODIS. A caracterização da sazonalidade foi realizada em áreas com e sem registro de queimadas. Para construção das séries temporais foi utilizado o produto M0D1301. As imagens datam do período de 2000 a 2015, com um período de amostragem a cada 16 dias. As transformações de Fourier de séries temporais mostram que os índices de vegetação do Cerrado são amplamente dominados pelo ciclo anual. 0 comportamento dos índices de vegetação estabelecida para o período 2000-2015 é fortemente controlado pela precipitação estabelecida em relação ao mesmo período. Em alguns anos, os índices de vegetação mostram uma dinâmica mais propagada durante a estação chuvosa (aumento prematuro e amplitude menor do que a amplitude média de climatologia), ou ao contrário, uma atividade mais tardia e mais ampla. Os diagramas de dispersões entre os índices de vegetação obtidos para os locais sem fogo contra os locais queimados, mostram uma separação de dados em três grupos distintos: os índices de vegetação da estação das chuvas, os da estação seca, e, finalmente, os índices que comportam uma assinatura relacionada com o fogo.

Palavras-chave: EVI, NDVI, precipitação, fogo, sensoriamento remoto.

\section{Abstract}

This study aims to characterize the seasonal behavior of Cerrado vegetation through vegetation indexes (NDVI and EVI) of the MODIS sensor. The characterization of seasonality was carried out in areas with and without recorded fires. NDVI and EVI vegetation indexes from the MOD1301 product were used to build time series. The images date from 2000 to 2015, with a 16-day sampling period. Fourier transformations of time series show that the Cerrado vegetation indexes are largely dominated by the annual cycle. The monthly climatology of vegetation indexes established for the period 2000-2015 is strongly controlled by the rainfall monthly climatology established over the same period. In some years the vegetation indexes show a more dynamic spread during the rainy season (a premature increase and lower amplitude than the average amplitude of climatology), or on the contrary a later and more extensive activity. Dispersion diagrams between vegetation indexes obtained for sites without fire versus the burned sites show a separation of data into three distinct 
Artigo

groups: the vegetation indexes of the rainy season, those in the dry season, and finally the indexes with a fire-related signature.

Keywords: EVI, NDVI, precipitation, fire, remote sensing.

Résumé

Cette étude vise à caractériser le comportement saisonnier de la végétation du Cerrado par indice de végétation (NDVI et EVI) du capteur MODIS. La caractérisation de la saisonnalité a été réalisée dans les zones avec et sans registre de brûlées. Pour la construction de la série de temporelle, nous avons utilisé le MOD1301. Les images datent de 2000 à 2015, avec une période d'échantillonnage tous les 16 jours. La série chronologique des transformations de Fourier montrent que les indices de végétation du Cerrado sont largement dominés par le cycle annuel. Le comportement des indices de végétations établies pour la période 2000-2015 est fortement contrôlé par la précipitation sur la même période. En quelques années, les indices de végétation montrent une propagation plus dynamique pendant la saison des pluies (début prématuré et une amplitude inférieure à I'amplitude moyenne de la climatologie), ou plutôt une activité plus en retard et plus large. Les diagrammes de dispersion entre les indices de végétation obtenus pour les sites sans feu contre les sites brûlés, montrent une séparation des données en trois groupes distincts : les indices de végétation de la saison des pluies, saison sèche, et enfin les indices qui contiennent une signature liée à l'incendie.

Mots clés: EVI, NDVI, précipitation, feu, la télédétection.

Introdução

O bioma Cerrado ocupa, aproximadamente, 2 milhões de $\mathrm{km}^{2}$, isto corresponde a $23 \%$ do território brasileiro (IBGE, 2004). O bioma é formado por um mosaico heterogêneo de fisionomias vegetais (Eiten, 1972; OliveiraFilho e Ratter, 2002) que abriga rica diversidade florística (Ratter et al., 2000). A função e estruturação da vegetação são determinadas por uma interação complexa de fatores bióticos e abióticos. Sob outra perspectiva, a cobertura vegetal exerce papel fundamental nos sistemas climáticos, por meio das trocas de energia, água e gases com a atmosfera e a produção e sequestro de gases do ciclo biogeoquímico (Sellers et al., 1997).

O Cerrado apresenta grande contraste sazonal entre a estação seca e a estação chuvosa. A marcante sazonalidade climática exerce forte influência na fenologia da vegetação, algumas fisionomias perdem total ou parcialmente as folhas na estação seca e ocorre a produção de novas folhas, aumento da biomassa e ativação dos processos metabólicos na estação chuvosa (Klink; Solbrig, 1996; Ratter et al., 1997). Essa estreita relação das condições climáticas com a vegetação tem sido objeto de diversos estudos que mostram a importância da precipitação no padrão de distribuição espacial e temporal da vegetação (Justice et al., 1986; Malo e Nicholson, 1990; Yang et al., 1997; Wang et al., 2003; Weiss et al., 2004; Huete et al., 2006) e na previsibilidade dos estados da vegetação e da produção primária (Mangiarotti et al., 2010; 2012). 
Essas análises tem sido escopo de estudos em diversas regiões do mundo. Weiss et al. (2004) e Yang et al. (1997) conduziram essas análises nos Estados Unidos empregando dados do sensor Advanced Very High Resolution Radiometer (AVHRR), Justice et al. (1986) e Mangiarotti et al. (2012) também usaram dados do mesmo sensor em análises no continente Africano. No caso brasileiro, Huete et al. (2006) investigaram o padrão sazonal e fenologia do bioma Amazônia empregando dados do Moderate Resolution Imaging Spectroradiometer (MODIS).

A obtenção de dados por sensoriamento remoto é baseada na radiação eletromagnética que o alvo na superfície terrestre reflete ou emite. $\mathrm{O}$ comportamento espectral de cada alvo depende das suas características físicas, biológicas ou químicas. A energia emitida e/ou refletida é transformada em produto passível de leitura por um sensor (Novo, 2008). Uma das ferramentas do sensoriamento remoto que visa mensurar variáveis relacionadas a processos físicos, químicos e biológicos da vegetação, incêndios florestais, propriedade e dinâmica das nuvens é o sensor MODIS (Salomonson; Toll, 1990).

O sensor MODIS veio preencher uma lacuna na disponibilidade efetiva de dados de sensoriamento remoto de alta resolução temporal e espectral e moderada resolução espacial, voltados para aplicações sobre a dinâmica terrestre, além da melhoria das correções geométrica e atmosférica (Rizzi; Rudorff, 2007). O MODIS possui numerosos produtos derivados das suas imagens para aplicações em escala global e regional. Entre eles, o MOD13Q1 relaciona-se com o estudo da vegetação fornecendo os índices de vegetação NDVI (Normalized Difference Vegetation Index) (Rouse et al., 1973) e EVI (Enhanced Vegetation Index) (Justice et al., 1998).

Esses índices são produzidos globalmente com 1 km, 500 m e $250 \mathrm{~m}$ de resolução e composições no período de 16 dias. A baixa resolução espacial dos dados é compensada pela alta frequência temporal. Essa alta resolução temporal permite a construção de séries contínuas, isso possibilita discriminar flutuações sazonais. Esses índices de vegetação fornecem comparações consistentes de dados temporais e espaciais das condições da vegetação, além de possibilitar monitorar a atividade fotossintética da vegetação em suporte a detecção de mudança e interpretações biofísicas e da fenologia.

Nesse contexto, o escopo do presente estudo tem como objetivo caracterizar a dinâmica sazonal da vegetação do Cerrado no DF por meio das séries temporais do NDVI e EVI do sensor MODIS. 
Materiais e métodos

Área de estudo

As áreas de estudo localizam-se em unidades de conservação de proteção integral no DF: Estação Ecológica do Jardim Botânico (ESEC-JB); Estação Ecológica da UnB (ESEC-UnB); Parque Nacional de Brasília (PARNA-Brasília); Reserva Biológica da Contagem (RBC) (Fonte: Elaborado pelos autores. Figura 1). Foram selecionadas duas formações vegetais do Cerrado com base no mapeamento de uso e cobertura do solo do Zoneamento Ecológico-Econômico do DF: Cerrado sentido restrito (formações savânicas) e Campos naturais (formações campestres). Essas são as duas classes de cobertura de vegetação nativas mais representativas nas unidades de conservação do DF (GDF, 2010). As áreas de estudo dentro dessas unidades de conservação foram escolhidas após o cruzamento espacial das áreas de Cerrado sentido restrito e Campos naturais em áreas com e sem registro de queimadas no período de 2000 a 2010, totalizando nove áreas.
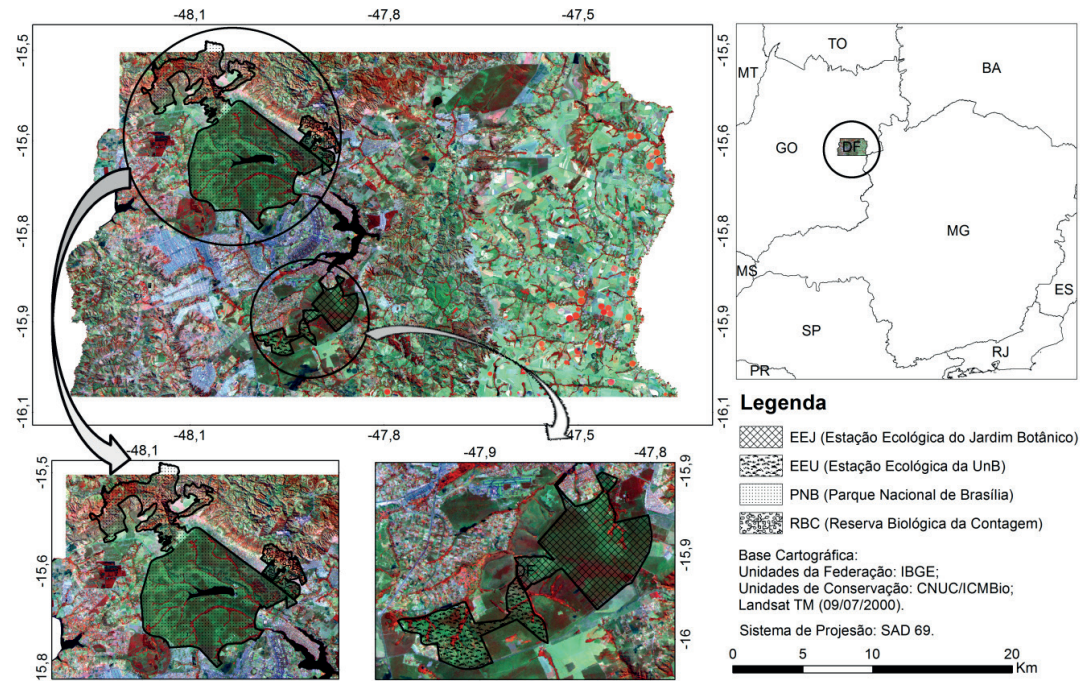

Figura 1 - Mapa de localização das unidades de conservação no DF que tiveram áreas selecionadas para o presente estudo. ESEC-JB e ESEC-UnB localizadas na porção sul do DF e PARNA-Brasília e RBC localizadas na porção norte. 
A base de dados de incêndios florestais utilizada foi elaborada por Silva (2010) para os anos 2000 a 2010. Silva (2010) utilizou imagens do Satélite Landsat TM-5 (órbita 221 e ponto 71). As datas de aquisição das imagens são preferencialmente entre os meses de julho e setembro, meses com maior registro de incêndios na região. Essas imagens foram transformadas pela Análise de Componentes Principais (ACP), removendo a correlação entre as bandas. Estas novas imagens foram analisadas e alguns componentes foram utilizados pela metodologia Árvore de Decisão para detecção de áreas afetadas pelo fogo (Silva, 2010).

\section{Dados: índices de vegetação NDVI e EVI}

No presente estudo, os dados utilizados para análise do padrão sazonal das duas fisionomias do Cerrado em unidades de conservação no DF são oriundos dos índices de vegetação NDVI e EVI disponibilizado pelo sensor MODIS instrumento do satélite TERRA.

O NDVI é sensível à clorofila (Huete et al., 2002) e fornece informações sobre detecção de mudanças vegetais e parâmetros biofísicos do dossel. Esse índice foi proposto por Rouse et al. (1973) e consiste numa relação entre as medidas espectrais da banda do infravermelho próximo (858nm) e vermelho (645nm), conforme a equação a seguir (equação 1):

$$
\mathrm{NDVI}=(\rho \mathrm{IVP}-\mathrm{rV}) /(\rho \mathrm{IVP}+\mathrm{rV})
$$

Onde $\rho I V P$ é a reflectância na banda do infravermelho próximo e $r V$ é a reflectância na banda do vermelho.

Outro índice de vegetação amplamente empregado em estudos da vegetação é o EVI. Este índice foi desenvolvido para melhorar a detecção do sinal da vegetação em regiões com maior densidade de biomassa, reduzindo problemas de saturação, e, ainda, reduzir a influência da interferência do solo e da atmosfera na resposta da vegetação (Justice et al., 1998; Huete et al., 2002). O EVI é calculado com base na equação 2 (Justice et al., 1998).

$$
E V I=G^{*}(\rho I V P-\rho V) /\left(L+\rho I V P+C 1^{*} \rho V-C 2^{*} \rho A\right)
$$

Onde $\rho I V P$, $\rho V$ e $\rho A(469 \mathrm{~nm})$ são, respectivamente, reflectância no infravermelho próximo, reflectância no vermelho e reflectância no azul; L é o fator de ajuste para os componentes abaixo do dossel (canopy background), C1 e C2 são os coeficientes para ajuste das resistências dos efeitos dos aerossóis da atmosfera; e $\mathrm{G}$ fator de ganho. Os valores desses coeficientes 
adotados pelo algoritmo do EVI são $\mathrm{L}=1, \mathrm{C} 1=6, \mathrm{C} 2=7,5$ e $\mathrm{G}=2,5$ (Huete et al., 1997; Justice et al., 1998). O EVI é mais sensível às variações na resposta estrutural do dossel, incluindo o índice de área foliar, a fisionomia da planta e a arquitetura do dossel (Huete et al., 2002).

Os índices de vegetação do produto MOD13Q1 têm como origem os dados do MOD09, nível 2, que geram dados de reflectância diariamente da superfície com as devidas correções dos efeitos da atenuação atmosférica. Os dados são corrigidos dos efeitos de espalhamento molecular, absorção de ozônio e aerossóis (Huete et al., 2002). Um algoritmo utiliza esses dados para gerar índices de vegetação, nível 3, com composições de 16 dias das refletâncias bidirecioniais diárias. Esse algoritmo processa os dados do MOD09 para gerar os índices de vegetação NDVI e EVI com 250m (Sampaio, 2007).

As imagens MOD13Q1 foram extraídas do portal (http://reverb. echo.nasa.gov/reverb/) que integra o programa EOSDIS da NASA (The Earth Observing System Data and Information System), que visa fornecer dados de observação da Terra para a comunidade científica do mundo todo de forma fácil e confiável (KOBLER; BERBERT, 1991). As imagens foram adquiridas no período de fevereiro de 2000 a dezembro de 2015. Cada imagem resulta de um mosaico da seleção dos pixels com melhor qualidade de um período de 16 dias. Assim, foi obtido 363 imagens que cobrem todo o período de observação.

\section{Pré-tratamento e análise dos dados}

A cena h13v10 recobre toda a área de estudo. Originalmente as imagens estavam na projeção integerized sinusoidal e foram reprojetadas para o sistema de projeção geográfica LAT/LONG, utilizando o Datum SAD-69. Para caracterizar e analisar de modo simplificado a sazonalidade da vegetação do Cerrado a partir dos dados utilizados, o estudo foi concentrado em três tipos de informações: a) o espectro de Fourier das séries temporais de NDVI e EVI que permite identificar as principais periodicidades de sinal da vegetação; b) as anomalias interanuais de EVI e NDVI comparado a uma "climatologia" representativa nos anos 2000 a 2015; c) as correlações eventuais entre os índices de vegetação, tipos de vegetação, tipos de fisionomia vegetal presentes no cerrado e incêndios. 


\section{Espectros de Fourier dos índices de vegetação}

Primeiro foi obtido de cada série temporal do índice de vegetação (NDVI ou EVI) o seu valor médio. Observou-se que esta reorientação de cada série é suficiente para remover todas as tendências lineares ao longo do período de 16 anos de observação. Em seguida, foi realizada uma transformada de Fourier convencional (Priestley, 1981) para cada série temporal, o qual inclui os 363 pontos espaçados de 16 dias. Assim, o período de Nyquist é de aproximadamente um mês (32 dias para ser exato) e o período mais longo detectável é de 16 anos.

\section{Anomalias interanuais dos índices de vegetação}

Primeiro foi obtido de cada série temporal de índice de vegetação (NDVI ou EVI) o valor médio das amostras por vegetação. Observou-se que esta reorientação de cada série é suficiente para remover qualquer tendência linear ao longo do período. Para determinar a magnitude das mudanças nos índices de vegetação de Cerrado de um ano para o outro e a distribuição destas variações por temporada e precipitação, tomou-se como referência climatologia estabelecida ao longo do período 2000-2015.

Nesta climatologia para cada mês, foi calculado o valor médio mensal dos índices de vegetação durante os 16 anos (por exemplo, para o mês de janeiro, a climatologia dá o valor médio de todos os dados obtidos durante o período observado de janeiro). As séries temporais de anomalias foram obtidas por meio da diferença entre a série temporal original do índice de vegetação em questão e sua série climatológica (repetida identicamente a cada ano sobre todo o período analisado). Em seguida, avaliou-se as correlações entre as séries temporais de precipitação e as séries temporais dos índices de vegetação (NDVI e EVI) do Cerrado.

\section{Índice de vegetação, fisionomia vegetal e fogo}

Para avaliar o comportamento de cada índice de vegetação (NDVI ou EVI) conforme o tipo de fisionomia vegetal e, ainda, segundo a ocorrência ou não de fogo. Foi produzido diagramas de dispersões entre os dados de NDVI e EVI associados a dois tipos distintos de fisionomia da vegetação, acrescentando mais informações, indicando se a data de observação por satélite corresponde a um período de chuva, seca ou se ele corresponde a 
uma área que foi submetida a um incêndio. Se um diagrama de dispersão mostra uma nuvem de pontos associada a eventos de fogo que se separa dos outros dados, então o índice de vegetação utilizado seria um bom candidato para a detecção e monitoramento de queimadas por satélite.

É importante ressaltar que somente nessa etapa foram utilizadas as áreas com ocorrência de queimadas. Os dados foram separados em períodos com registro de fogo, meses secos e meses chuvosos. O período definido com queimadas foi de agosto a outubro, que são os meses com maior incidência de fogo, esses meses só foram separados nos anos com queimadas. Outubro a abril foi considerado como a estação seca, e a estação chuvosa compreende de maio a setembro, conforme definido por Castro et al. (1994).

\section{Resultados e discussão}

\section{Sazonalidade dos índices de vegetação do Cerrado}

As Figuras 2a e 2b representam as análises de Fourier em áreas de Cerrado sentido restrito e Campos naturais para o NDVI e EVI. Observou-se primeiro que os espectros obtidos são bastante semelhantes entre o Cerrado sentido restrito e os Campos naturais.
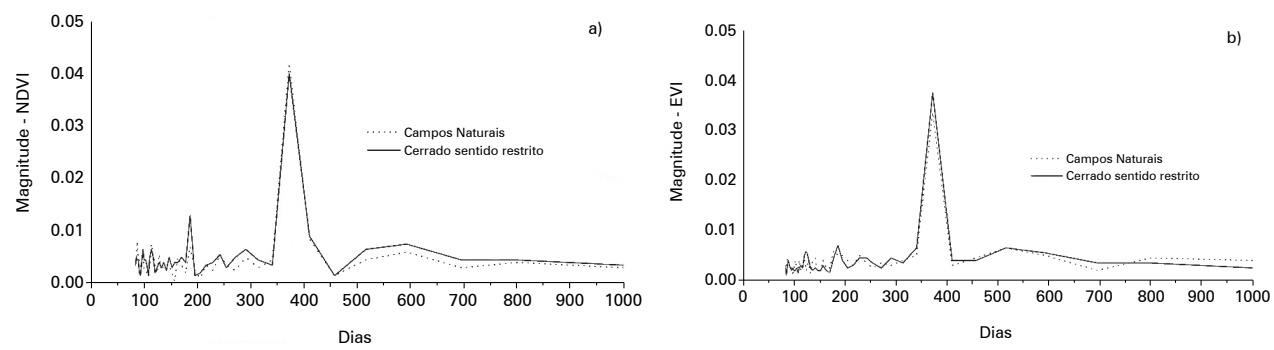

Figuras 2a e 2b - Espectros de amplitude das séries temporais dos índices NDVI e EVI do MODIS por meio da transformada de Fourier (na abscissa 0 período de dias): a) NDVI nas áreas de Cerrado sentido restrito e Campos naturais; b) EVI nas áreas de Cerrado sentido restrito e Campos naturais.

Fonte: Elaborado pelos autores.

A Figura 3 ilustra o comportamento médio mensal no período de 2000 a 2015 da precipitação juntamente com os índices NDVI e EVI nas 
classes de vegetação Cerrado sentido restrito e Campos naturais. É possível analisar os dois períodos bem marcantes que ocorrem no Cerrado, estação seca e a estação chuvosa. Infere-se que o período chuvoso é de outubro a abril e o período seco ocorre nos meses de maio a setembro, conforme constatado também por Castro et al. (1994). No presente estudo o período seco foi definido com precipitação menor que $100 \mathrm{~mm}$ (Becerra et al., 2009).

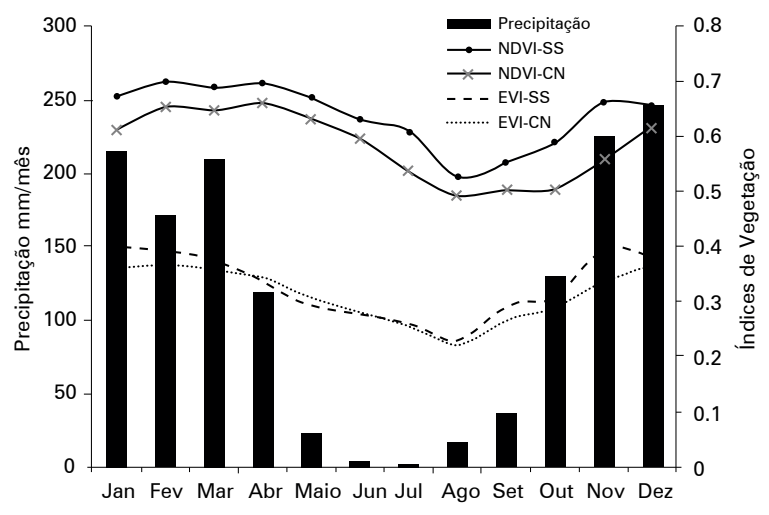

Figura 3 - Média climatológica do padrão sazonal da precipitação pluvial e dos índices de vegetação NDVI e EVI nas áreas de SS (Cerrado sentido restrito) e CN (Campos Naturais) no DF no período de 2000 a 2015.

Fonte: Elaborado pelos autores.

Os dois índices de vegetação delinearam satisfatoriamente o padrão sazonal da precipitação. Aumento dos índices de vegetação devido à alta atividade fotossintética e maior biomassa, reflexo do aumento da precipitação. Decréscimo dos índices devido à redução das taxas fotossintéticas e redução da fitomassa foliar com a diminuição da precipitação pluvial. Nesse sentido, as duas classes de vegetação do Cerrado utilizadas neste estudo são fortemente influenciadas pelo regime de chuvas. Observa-se que a queda dos índices de vegetação com a diminuição da precipitação pluvial é mais gradual do que o crescimento dos índices quando a chuva começa. Com o início das primeiras chuvas a vegetação responde mais rapidamente, o que reflete no crescimento mais rápido do NDVI e EVI. A queda mais lenta dos índices de vegetação ocorre devido às reservas de água no solo do cerrado que ficam disponíveis para as plantas. 
As características das espécies do cerrado também corroboram, pois apresentam folhas coriáceas, cascas grossas que minimiza a perda de água e raízes profundas. Contudo, nem todas as fisionomias do Cerrado são tão influenciadas pelo padrão sazonal da precipitação, a maior disponibilidade de água próxima a rios aliada a adaptação de muitas espécies do Cerrado com raízes profundas proporciona maior estabilidade da atividade fotossintética e manutenção da fitomassa foliar (Huete et al., 2006).

A Tabela 1 - Correlação do NDVI e EVI com dados de precipitação pluviométrica para um período com zero, um, dois e três e nenhum mês de defasagem (SS: Cerrado sentido restrito; CN: Campos naturais) mostra os valores das correlações entre o NDVI e EVI em áreas de Cerrado sentido restrito e Campos naturais com a variável climática precipitação para diferentes valores de defasagem.

Tabela 1 - Correlação do NDVI e EVI com dados de precipitação pluviométrica para um período com zero, um, dois e três e nenhum mês de defasagem (SS: Cerrado sentido restrito; CN: Campos naturais).

\begin{tabular}{|c|c|c|c|c|c|}
\hline Atraso(meses) & $\mathbf{0}$ & $\mathbf{1}$ & $\mathbf{2}$ & $\mathbf{3}$ & $\mathbf{4}$ \\
\hline NDVI-CN & 25,7 & 59,9 & 64,1 & 57,5 & 34,2 \\
\hline NDVI-SS & 29,6 & 61,7 & 62,1 & 49,3 & 26,2 \\
\hline EVI - SS & 68,9 & 64,1 & 41,3 & 15,0 & $-22,8$ \\
\hline EVI - CN & 64,4 & 66,4 & 52,3 & 27,8 & $-3,4$ \\
\hline
\end{tabular}

Fonte: Elaborado pelos autores.

As máximas correlações entre o NDVI e EVI e a precipitação em áreas de Cerrado sentido restrito e Campos naturais mostrou coeficiente superior a $60 \%$, o que denota uma relação direta dessas variáveis. Com defasagem de dois meses para o NDVI em áreas de Cerrado sentido restrito e Campos naturais são encontrados os maiores coeficientes de correlação, com 64,1\% para Campos naturais e 62,1\% para Cerrado sentido restrito. Para o EVI em áreas de Cerrado sentido restrito a maior correlação ocorre no mês corrente, em áreas de Campos naturais o maior coeficiente de correlação ocorre com um mês de defasagem. Esse atraso entre os eventos de chuvas sazonais e a resposta do NDVI também já foi verificado nas savanas africanas (Justice et al., 1986; Jarlan et al., 2005). A melhor correlação entre o NDVI e a precipitação ocorre entre o mês corrente e os dois meses seguintes (Malo; Nicholson, 1990). 


\section{Anomalias interanuais sazonais}

As anomalias dos índices de vegetação nas duas formações vegetais de interesse - Campos naturais e Cerrado sentido restrito - são apresentadas na Figura 4a para o NDVI e a Figura 4b para o EVI. Uma anomalia é a diferença do índice em um determinado mês e os valores do índice médio obtido 2000-2015 no mesmo mês (climatologia).

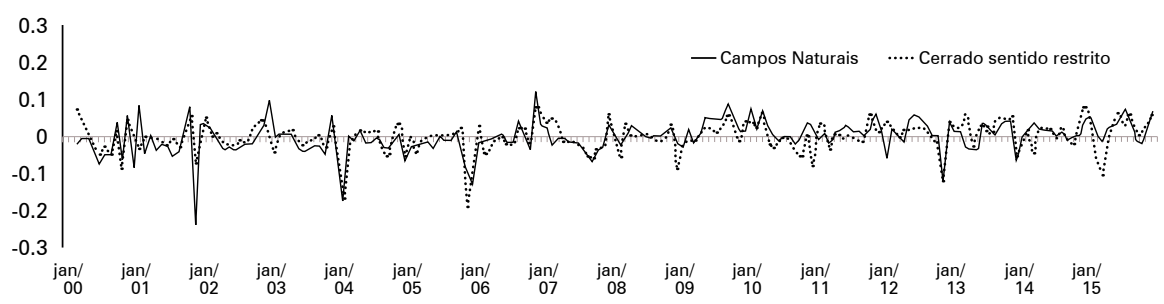

Figura 4a

Fonte: Elaborado pelos autores.

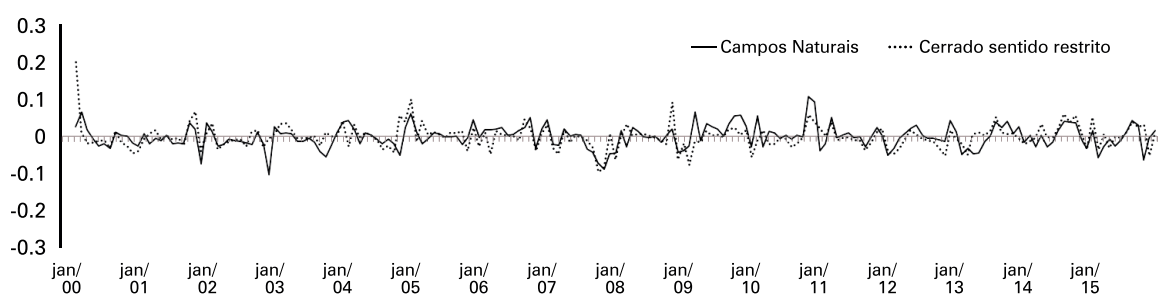

Figura $4 b$

Fonte: Elaborado pelos autores.

As linhas que apresentam as anomalias do NDVI e EVI entre as áreas de Cerrado sentido restrito e Campos naturais apresentam a mesma tendência, ou seja, não há diferença substancial entre as anomalias dessas duas formações. As séries de anomalias do NDVI em áreas de Cerrado sentido restrito e Campos naturais mostram que há uma anomalia negativa acentuada do NDVI no segundo semestre dos anos 2001, 2003, 2005 e 2012. Anomalias negativas apontam períodos mais secos. Em 2003, 2006 e 2009 observa-se anomalias positivas do NDVI. 
No perfil de anomalias do EVI os períodos com as maiores anomalias negativas ocorreram em 2001, 2002, 2007 e entre 2008 e 2009, períodos considerados mais secos. O período com anomalias com valores mais positivos ocorreu entre 2005 e 2006, 2010 e 2014.

Observa-se que os períodos de anomalia entre o NDVI e EVI são, em geral, distintos, isso reforça o fato que esses dois índices de vegetação respondem de forma diferente aos fatores ambientais. Ao comparar o comportamento da série temporal de anomalias do NVI e EVI com o da precipitação não é possível observar semelhança de forma clara. Como citado anteriormente, há um lapso na resposta da vegetação com eventos de chuvas, ainda, há outros fatores naturais que conduzem o comportamento da vegetação.

A Figura 5 apresenta a dispersão da precipitação pluvial com os índices de vegetação NDVI e EVI nas respectivas fisionomias do Cerrado estudadas neste trabalho. Os maiores coeficientes de determinação foram obtidos com o índice de vegetação EVI, 0,4747 e 0,4145 nas classes de Cerrado sentido restrito e Campos naturais, respectivamente. Já o NDVI apresentou valores de 0,0878 e 0,066 para Cerrado sentido restrito e

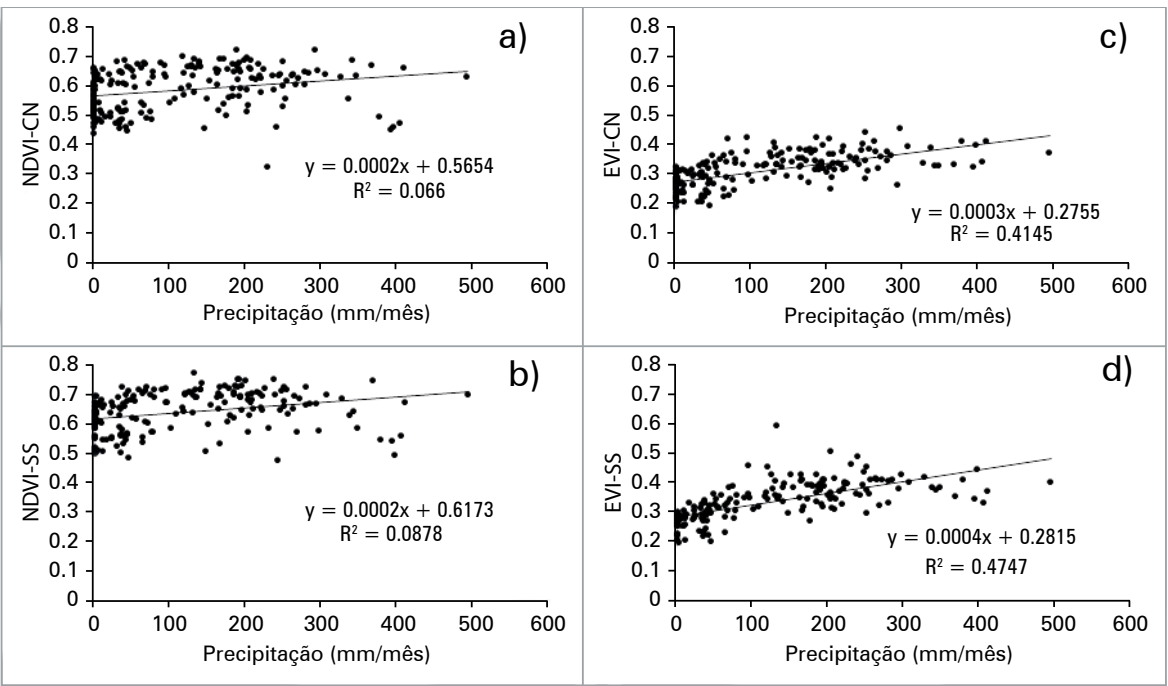

Figura 5 - Gráficos de dispersão a partir de uma regressão linear entre a precipitação pluvial e os índices de vegetação NDVI e EVI : a) NDVI em fisionomias de CN; b) NDVI em áreas naturais de SS no DF; c) EVI em fisionomias de CN no DF; d) EVI em áreas naturais de SS no DF. 
Campos naturais, respectivamente. O coeficiente de determinação $\left(\mathrm{R}^{2}\right)$ denota o quanto as variáveis dependentes estão sendo explicadas pelas variáveis independentes. Para o NDVI verificou-se que os valores das variáveis independentes estão explicando muito pouco a variável dependente, por outro lado, o EVI melhora bastante esse parâmetro.

Por meio do deste de hipótese para o coeficiente angular $(\beta 1)$, ao nível de significância de $5 \%$, verificou-se que os $\beta 1$ são diferentes de zero. O valor-p para as regressões do EVI em áreas de Cerrado sentido restrito

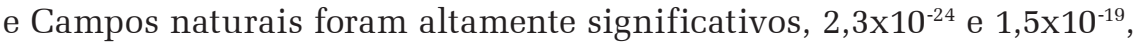
respectivamente. O valor-p para o NDVI em áreas de Cerrado sentido restrito e Campos naturais foi de $4,7 \times 10^{-4}$ e $4,4 \times 10^{-3}$, respectivamente.

\section{Índice de vegetação e fogo}

Para examinar se os incêndios que ocorrem nas áreas de estudo têm uma assinatura detectável nos índices de vegetação construídos a partir dos dados do sensor MODIS e também se essas assinaturas são diferentes das assinaturas de vegetação na estação chuvosa e no período de seca, produzimos gráficos de dispersão, colocando na abscissa as áreas onde ocorreu fogo e ordenou-se os dados dos locais onde não houve queimada (zonas de referência). Além disso, atribui-se aos pontos dos diagramas três símbolos distintos correspondentes aos dados obtidos durante a estação chuvosa, estação seca, ou quando os dados do eixo das abscissas foram obtidos em uma zona que foi queimada no mesmo ano, antes ou durante a obtenção dos dados (utilizando um mosaico de pixels obtidos ao longo de um período de 16 dias).

Na Figura 6 são mostrados os diagramas de dispersões obtidos com o NDVI do Cerrado sentido restrito e dos Campos naturais. Resultados semelhantes foram relatados para o EVI na Figura 7.

Foi observado padrões similares de distribuição de dados sobre os quatro diagramas. De fato, os dados obtidos durante a estação chuvosa se agruparam em direção ao quadrante superior direito correspondente a altos valores de índices de vegetação. Em vez disso, os dados obtidos na estação seca se reuniram no quadrante inferior esquerdo, correspondente a valores relativamente baixos de índices de vegetação, de acordo com uma atividade fotossintética muito limitada, como pode ser observado no campo. No entanto, em cada diagrama, verifica-se que estas duas nuvens de pontos tendem a se alinhar sobre uma mesma regressão, mas com uma dispersão 
dos dados mais importante para os valores do índice na estação chuvosa do que na estação seca (comparar os coeficientes $\mathrm{R}^{2}$ associados com regressões parciais separando cada nuvem de pontos - ver Figura 6 e Figura 7).

Os pontos dos diagramas em que o eixo da abscissa corresponde a um determinado local queimado se separaram claramente das duas nuvens de pontos anteriores. No entanto, não se alinham ao longo da linha de regressão descrita acima, mas os índices de vegetação das áreas queimadas têm valores muito baixos em relação aos valores de índice dos locais não perturbados. Isso se reflete nos diagramas com linhas de regressão quase horizontais, os NDVI (EVI respectivamente) dos locais queimados cobriram uma gama de valores de cerca de [0,15-0,4] (respectivamente [0,05-0,2]).
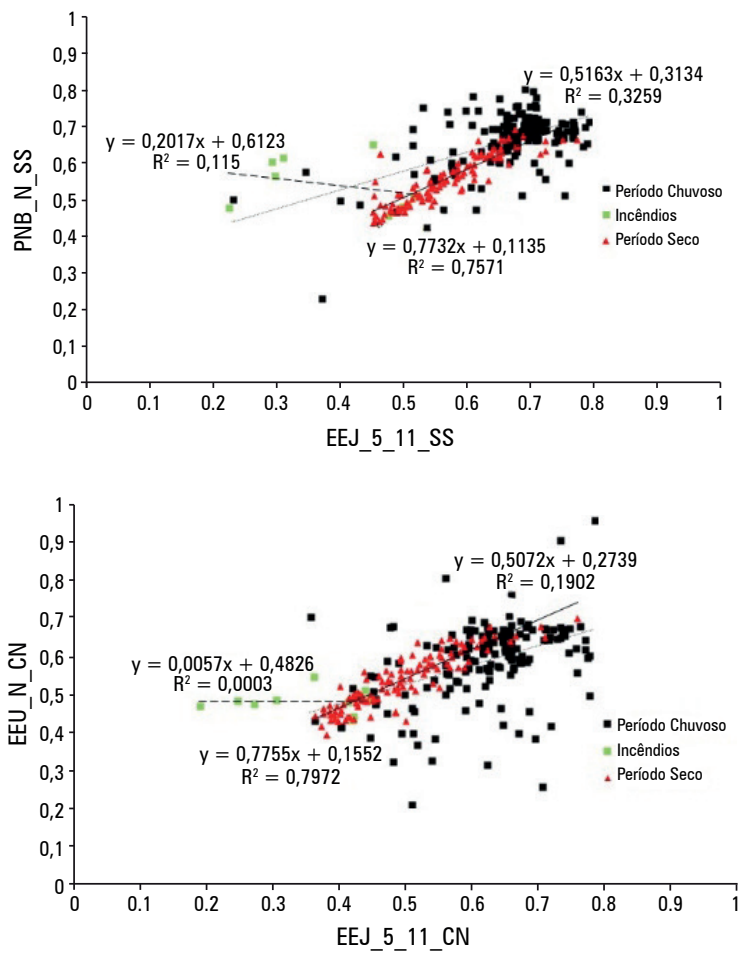

Figura 6 - Ajuste do coeficiente de determinação do NDVI entre as áreas em estudo para o período seco, chuvoso e com registro de incêndios. 

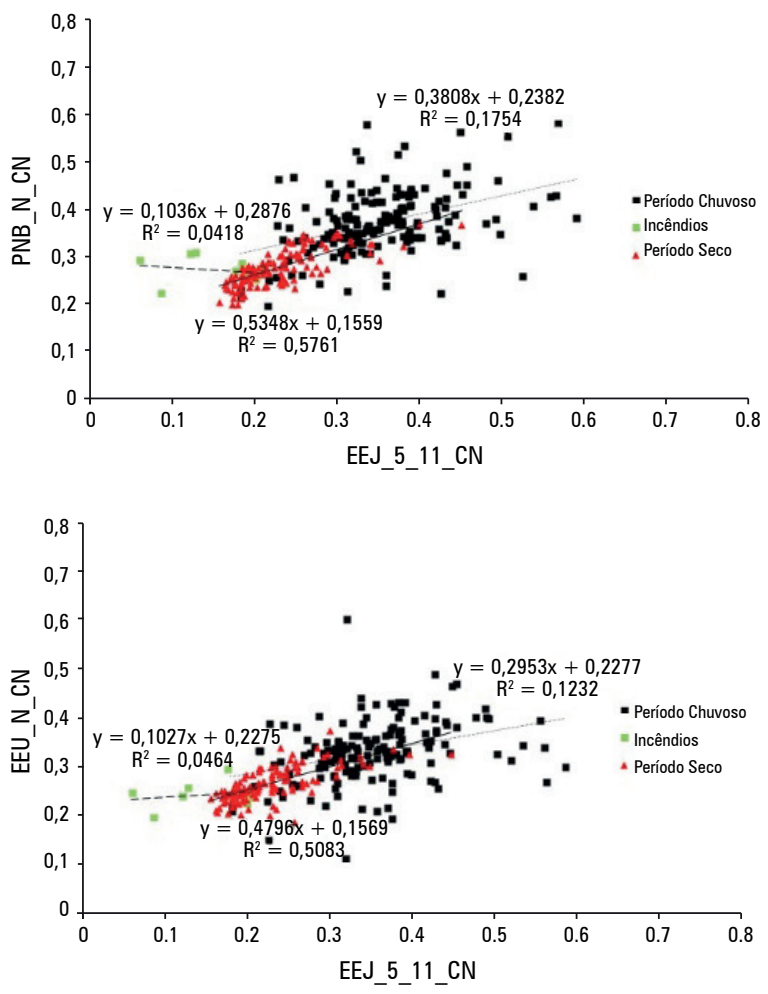

Figura 7 - Ajuste do coeficiente de determinação do EVI entre as áreas em estudo para o período seco, chuvoso e com registro de incêndios.

Fonte: Elaborado pelos autores.

O coeficiente empírico destas linhas é próximo de zero, pois os dados da ordenada são obtidos em zonas de referência não afetadas pelos incêndios. O fato importante é que este tipo de diagrama, que utiliza os dados do MODIS das áreas queimadas e de referências, pode distinguir as áreas afetadas pelo fogo local (e, por conseguinte, de datar estes eventos).

Uma análise detalhada da dinâmica da restauração pós-fogo da vegetação do Cerrado sugere que a assinatura do fogo desaparece a partir dos dados do sensor MODIS depois de cerca de 3,0 a 3,5 meses (Souza, 2014). Este resultado deve ser confirmado estatisticamente e refinado em função de um maior número de dados obtidos em um período de restauração pós-fogo na vegetação do cerrado. 
Considerações finais

Os resultados mostraram que os perfis dos índices de vegetação (NDVI e EVI) definiram satisfatoriamente a forte sazonalidade climática na região avaliada. A inclusão da série história de precipitação permitiu o melhor entendimento da dinâmica sazonal do Cerrado.

Os dados de precipitação mostraram que a dinâmica da vegetação é fortemente influenciada pelo regime de chuvas, maiores valores no período chuvoso (outubro a abril) e redução no período seco (maio a setembro). Conforme a transformada de Fourier nas figuras 2a e 2b, verifica-se que em um ano no Cerrado há um ciclo sazonal completo, período seco e chuvoso.

Os resultados das correlações mostraram ajuste positivo entre os índices e a precipitação, o que aponta que a precipitação é um fator que direciona o crescimento da vegetação. O EVI foi o índice que apresentou maior correlação, possivelmente por ser um índice melhorado e não apresentar problemas de saturação.

Verifica-se que há uma defasagem na reposta da vegetação quando há alterações na precipitação pluvial. A maior correlação do NDVI com a precipitação foi obtida com dois meses de atraso em áreas de Cerrado sentido restrito e Campos naturais. Em áreas de Cerrado sentido restrito para o EVI a maior correlação ocorreu no mês corrente e em áreas de Campos naturais o maior coeficiente foi verificado com um mês de atraso. Ressalta-se que outras variáveis ambientais exercem influência sobre a dinâmica da vegetação e que precisa ser estudado, para o completo entendimento do mecanismo de influência do clima sobre os índices de vegetação.

O período chuvoso, seco e com ocorrência de queimadas apresentam comportamento espectral bem distinto entre si, de tal forma que é possível identificá-los em um gráfico de coeficiente de determinação. Esses resultados retratam a importância dos índices de vegetação para estudos relacionados ao fogo na vegetação do tipo cerrado. Em especial, os índices derivados do sensor MODIS, que devido a sua periodicidade e facilidade de acesso aparecem como uma importante fonte de dados para esse tipo de estudo. 


\section{Referências}

BECERRA, J. A. B.; SHIMABUKURO, Y. D.; ALVALÁ, R. C. S. Relação do padrão sazonal da vegetação com a precipitação na região de cerrado da Amazônia legal, usando índices espectrais de vegetação. Revista Brasileira de Meteorologia, v. 24, n. 2, p. 125-134, 2009.

CASTRO, L. H. R.; MOREIRA, A. M.; ASSAD, E. D. Definição e regionalização dos padrões pluviométricos dos Cerrados brasileiros. In: ASSAD, E. D. Chuvas nos Cerrados: análise e espacialização. Brasília, Embrapa-CPAC/Embrapa-SPI, 1994. $423 \mathrm{p}$.

EITEN, G. The cerrado vegetation of Brazil. The Botanical Review, v. 38, p. 201341. 1972.

FELFILI, J. M. Perda da diversidade. In: UNESCO. Vegetação no Distrito Federal: tempo e espaço. Brasília: 2000. 92 p.

GDF. Governo do Distrito Federal. Zoneamento Ecológico Econômico. 2010. Disponível em <http://www.zee-df.com.br/>. Acesso em: 23 jan. 2013.

HUETE, A. R. et al. Amazon rainforests green-up with sunlight in dry season. Geophysical Research Letters, v. 33, L06405, 2006.

HUETE, A. R. et al. A comparison of vegetation indices over a global set of TM images for EOS-MODIS. Remote Sensing of Environment, v. 59, p. 440-451, 1997.

HUETE, A.; DIDAN, K.; MIURA, T.; RODRIGUEZ, E. Overview of the radiometric and biophysical performance of the MODIS vegetation indices. Remote Sensing of Environment, v. 83, n. 1-2, número especial, p. 195-213. 2002.

IBGE. Mapa de biomas do Brasil: escala 1:500.000. 2004. Disponível em: <ftp:// ftp.ibge.gov.br/Cartas_e_Mapas/Mapas_Murais/>. Acesso em: 21 jan. 2013.

JARLAN, L. et al. Dominant patterns of AVHRR NDVI interannual variability over the Sahel and linkages to keyclimate signals (1982-2002). Geophysical Research Letters, v. 32, L04701, 2005.

JUSTICE, C. O. et al. The Moderate Resolution Imaging Spectroradiometer (MODIS): land remote sensing for global change research. IEEE Transactions on Geoscience and Remote Sensing, v. 36, n. 4, p. 1228-1247, 1998.

JUSTICE, C. O.; HOLBEN, B. N.; GWYNNE, M. D. Monitoring East African vegetation using AVHRR data. Int. J. Remote Sensing, v. 7, p. 1453-1474, 1986.

KLINK, C. A.; SOLBRIG, O. T. Efeito do fogo na biodiversidade de plantas do cerrado. In: SARMIENTO, G.; CABIDO, M. (Ed.). Biodiversidad y funcionamento de pastizales y sabanasen América Latina. Mérida: Cyted y Cielat, 1996, p. 231-244.

KOBLER, B.; BERBERT, J. NASA Earth Observing System Data Information System (EOSDIS), Digest of Papers: 11th IEEE Symp. Mass Storage Systems, IEEE Computer Soc. Press, Los Alamitos, CA, 1991, p.18-19.

MALO, A. R.; NICHOLSON S. E. A study of rainfall and vegetation dynamics in the African Sahel using normalized diVerence vegetation index. Journal of Arid Environments, v. 19, p. 1-24,1990. 
MANGIAROTTI, S. et al. The vegetation cycle in west Africa from AVHRR NDVI data: horizons of predictability versus spatial scales. Remote Sensing of Env., v. 114, p. 2036-2047, 2010.

MANGIAROTTI, S. et al. Predictability of the Vegetation Cycles over the semiarid region of Gourma (Mali) from forecasts of the AVHRR-NDVI signal. Remote Sensing of Environment, v. 123, p. 246-257, 2012.

NOVO, E. M. L. M. Sensoriamento Remoto: princípios e aplicações. 3. ed. São Paulo: Edgard Blucher, 2008. 363 p.

OLIVEIRA-FILHO, A. T.; RATTER, J. A. Fisionomias vegetais e floras nativas do Bioma Cerrado. In: OLIVEIRA, P. S.; MARQUIS, R. J. Marquis. (Org.). Os Cerrados do Brasil: ecologia e história natural de uma savana neotropical. New York: Columbia University Press, 2002. p. 91-120.

PRIESTLEY, M. B. Spectral Analysis and Time Series. 6. ed. London (UK): Academic Press, 1981.

RATTER, J. A. et al. Estudo preliminar da distribuição das espécies lenhosas da fitofisionomia cerrado sentido restrito nos estados compreendidos pelo bioma cerrado. Boletim do Herbário Ezechias Paulo Heringer, v. 5, n. 1, p. 5-43, 2000.

RATTER, J. A.; RIBEIRO, J. F.; BRIDGEWATER, S. The Brazilian cerrado vegetation and threats to its biodiversity. Annals of Botany, v. 80, p. 223-230, 1997.

RIZZI, R.; RUDORFF, B. F. T. Imagens do sensor MODIS associadas a um modelo agronômico para estimar a produtividade de soja. Pesq. agropec. bras. [online], v. 42, n. 1, p.73-80, 2007.

ROUSE, J. W. et al. Monitoring the vernal advancement of retrogradation (Green Wave Effect) of natural vegetation. Greenbelt: NASA/GSFC, 1974. 371 p. (Type III Final Report).

SALOMONSON, V. V.; TOLL, D. L. Execution phase (C/D) spectral band characteristics of the EOS Moderate Resolution Imaging Spectrometer (MODIS-N) facility instrument. Advances in Space Reserach, v. 2, n. 3, p. 231236, 1990.

SAMPAIO, C. S. Abordagem metodológica baseada nos dados multitemporais MODIS EVI/NDVI para classificação da cobertura vegetal na região do Parque Nacional da Chapada dos Veadeiros/GO. 73 f. Dissertação (Mestrado em Geografia) - Universidade de Brasília, Brasília, 2007.

SELLERS, P. J. et al. The impact of using area-averaged land surface properties topography, vegetation condition, soil wetness - In calculations of intermediate scale (approximately $10 \mathrm{~km}^{2}$ ) surface-atmosphere heat and moisture fluxes. Journal of Hydrology, v. 190, n. 3-4, p. 269-301,1997.

SILVA, C. M. J. Avaliação espaço-temporal dos incêndios florestais no Distrito Federal entre 1999 e 2010. 54 f. Monografia de projeto final em Sensoriamento Remoto - Universidade de Brasília, 2010.

SOUZA, G. M. Monitoramento sazonal e recuperação pós-fogo da vegetação do Cerrado usando dados do sensor MODIS. Mémoire d'Ingénieur Forestier. Fac. De Technologie, Dép. D’Ingéniérie Forestière: Université de Brasilia, 2014. 98 p. 
WANG, J.; RICH, P. M.; PRICE, K. P. Temporal responses of NDVI to precipitation and temperature in the central Great Plains, USA. International Journal of Remote Sensing, v. 24, n. 11, p. 2345-2364, 2003.

WEISS, J. L. et al. Seasonal and inter-annual relationships between vegetation and climate in central New Mexico, USA. Journal of Arid Environments, v. 57, p. 507-534, 2004.

YANG, Y.; YANG, L.; MERCHANT, J. W. An assessment of AVHRR/NDVI eco-climatological relations in Nebraska, USA. International Journal of Remote Sensing, v. 18, p. 2161-2180, 1997.

Greison Moreira de Souza - Possui Graduação em Engenharia Florestal pela Universidade de Brasília e Mestrado em andamento em Sensoriamento Remoto pelo Instituto Nacional de Pesquisas Espaciais - INPE.

Helen da Costa Gurgel - Possui Graduação em Geografia pela Universidade Federal Fluminense, Mestrado em Sensoriamento Remoto pelo Instituto Nacional de Pesquisas Espaciais e Doutorado em Geografia e Prática do Desenvolvimento pela Université Paris X. Realizou pós-doutorado no Instituto Nacional de Pesquisas Espaciais em parceria com o Institut de Recherche pour le Développement. Atualmente é professora adjunta do departamento de geografia da Universidade de Brasília.

Pierre Mazzega Ciamp - Possui Graduação em Maths-Physique pela Université Joseph Fourier (Grenoble I, França), Mestrado profissional em engenharia geofísica pela Université de Strasbourg I Louis Pasteur (França), Mestrado em ciências da Terra pela Université de Strasbourg I Louis Pasteur (França), Mestrado estudos aprofundados (DEA) em Astronomi pela Université de Toulouse III, Paul Sabatier. Possui Doutorado em Laboratoire d'Astrophysique de Toulouse pela Université Toulouse III Paul Sabatier (França). Atualmente é Diretor de Pesquisas no Centro Nacional de Pesquisa Científica (CNRS, França).

Contribuição de cada autor no desenvolvimento do artigo

Todos os autores ofereceram substanciais contribuições científicas e intelectuais ao desenvolvimento do artigo. Este consiste em um subproduto do trabalho de conclusão de curso do primeiro autor, sob orientação do segundo e terceiro autores. As tarefas de concepção e design do estudo, preparação e redação do manuscrito foram realizadas pelo primeiro autor, bem como a aquisição de dados e suas interpretação e análise. Coube ao segundo autor a orientação e desenvolvimento das técnicas de geoprocessamento e revisão crítica. Ao terceiro autor, coube o desenvolvimento das técnicas de análise para a reconstrução estatística do fenômeno estudado e a revisão crítica.

Recebido para publicação em 10 de setembro de 2016 Aceito para publicação em 19 de outubro de 2016 